\title{
PERANCANGAN MODEL PENGEMBANGAN KINERJA DAYA SAING KLASTER INDUSTRI MINYAK DAN GAS BUMI DI JAWA TIMUR
}

\author{
SYARIFA HANOUM, PATDONO SUWIGNJO, BUDISANTOSO WIRJODIRDJO DAN DEVINATA JUWITA P. \\ Jurusan Teknik Industri, Institut Teknologi Sepuluh Nopember (ITS) Surabaya
}

E-mail: syarifa@ie.its.ac.id

\begin{abstract}
ABSTRAK
Industri minyak dan gas merupakan sektor yang memiliki peranan vital strategis dalam pembangunan nasional. Jawa Timur salah satu dari provinsi di Jawa yang mempunyai potensi dahsyat dalam hal minyak dan gas yang belum dieksplorasi secara maksimal. Klaster industri adalah konsep pengembangan industri yang mengorganisasikan secara komprehensif hubungan dan kebiasaan dari stakeholder dalam industri sehingga mereka dapat berkorporasi untuk meningkatkan daya saing dalam industri. Peningkatan daya saing industri mendukung kemampuan dan kontribusi antara masing-masing industri minyak dan gas di Jawa dengan mengidentifikasi kebiasaan dari stakeholder dan sistem dalam sektor ini di mana akan menggambarkan model stakeholder dan model rantai pasok. Dalam penelitian ini, klaster industri pelumas digunakan sebagai embrio untuk mengembangkan klaster industri minyak dan gas. Kompleksitas dari sistem dalam contoh kebiasaan akan dipresentasikan dalam model sistem dinamis, di mana akan memungkinkan mengindentifikasi pengaruh antara masing-masing variabel. Model Porter's Diamond diadaptasi untuk memodelkan kebiasaan dalam daya saing. Hasil dari penelitian ini menunjukkan bahwa dalam meningkatkan daya saing klaster industri beberapa variabel signifikan dibanding yang lain.
\end{abstract}

Kata kunci: klaster industri minyak dan gas, stakeholder, analisa rantai nilai, analisa persaingan, sistem dinamis

\begin{abstract}
Oil and gas industry is a sector that has a vital strategic role on national development. East Java is one of the province in Java that has an enourmous potential on oil and gas and has not been optimally explored. Industrial cluster is an industrial development concept that comphrehensively organize the relationship and behaviour of stakeholder in industry so that they can co-operate to increase the competitiveness of the industry. The increasing of industrial competitiveness is supported by completeness and contribution of each industry in oil and gas industial cluster in each java by identifying the behaviour of stakeholder and system in this sector which is described in stakeholder model and value chain model. In this research, lubricant industrial cluster is used as an embryo for developing oil and gas industrial cluster. The complexity of the system in terms of system behaviour will be presented in a dynamic system model, which will make it possible to identify the influence between each variables.The Porter's Diamond model is adapted to model the behaviour of the competitiveness. The result of this research showed that in increasing the industrial cluster competitiveness some variables are significantly influencing then the others.
\end{abstract}

Key words: oil and gas industrial cluster, stakeholder, value chain analysis, competitiveness analysis, dynamic system

\section{PENDAHULUAN}

Indonesia adalah negara yang kaya akan potensi sumber daya alam, baik di sektor industri, pertanian, kehutanan, perikanan dan kelautan, dan pertambangan yang mampu memberikan sumbangan bagi pertumbuhan Product Domestic Bruto (PDB) setiap tahunnya. Pertumbuhan Product Domestic Bruto (PDB) tahun 2008 meningkat sebesar 6,1\% jika dibandingkan dengan tahun 2007. Pertumbuhan terendah terjadi di sektor pertambangan dan penggalian yaitu sebesar 5\% (Badan Pusat Statistik, 2009).

Kebijakan stimulus fiskal merupakan salah satu kebijakan yang akan membantu kinerja perekonomian tahun 2009. Sektor industri memang menyumbang PDB terbesar, tetapi sejak 2005 pertumbuhan sektor ini cenderung melambat. Bahkan pertumbuhannya berada di bawah pertumbuhan ekonomi. Oleh karena itu untuk mendukung perbaikan industri, kebijakan pemerintah akan difokuskan pada enam 
sektor prioritas dan kompetensi inti daerah. Enam sektor tersebut meliputi pemurnian minyak bumi, otomotif, pengolahan komoditas primer, industri pengolahan tembaga, industri tekstil dan produk tekstil terintegrasi, serta industri mesin perkakas (Gutomo, 2008). Struktur perekonomian Indonesia secara spasial masih didominasi oleh kelompok provinsi di Pulau Jawa yang mampu memberikan konstribusi terhadap Product Domestic Bruto (PDB) sebesar 57,9\% dengan konstribusi provinsi terbesar adalah DKI Jakarta, Jawa Timur, dan Jawa Barat, di mana ketiganya mampu memberikan konstribusi sebesar $46 \%$ yang menunjukkan hampir separuh konstribusi terhadap Indonesia dalam mendukung daya saing industri nasional (Badan Pusat Statistik, 2009). Jawa Timur (Jatim) merupakan salah satu propinsi di Indonesia dengan potensi sumber daya energi dan mineral yang beragam dan melimpah khususnya sumber daya mineral yaitu mineral energi meliputi minyak dan gas bumi serta panas bumi serta mineral bahan galian logam/ non-logam/ industri seperti pasir timah, sulfur, fosfat, mika, belerang, fluorit, felspar, ziolit dan diatomea. Industri Minyak dan Gas Bumi merupakan sektor penting di dalam pembangunan nasional baik dalam hal pemenuhan kebutuhan energi dan bahan baku industri di dalam negeri maupun sebagai penghasil devisa negara sehingga pengelolaannya perlu dilakukan seoptimal mungkin (Badan Pengelola Hilir Minyak dan Gas Bumi, 2009).

Dalam upaya menciptakan kegiatan usaha minyak dan gas bumi yang mandiri, andal, transparan, berdaya saing, efisien, dan berwawasan pelestarian fungsi lingkungan serta mendorong perkembangan potensi dan peranan nasional sehingga mampu mendukung kesinambungan pembangunan nasional guna mewujudkan peningkatan kemakmuran dan kesejahteraan rakyat maka ditetapkan Undangundang Nomor 22 Tahun 2001 tentang Minyak dan Gas (Badan Pengelola Hilir Minyak dan Gas Bumi, 2009), di mana pemerintah memberikan kesempatan besar bagi perusahaan multinasional serta mematahkan monopoli peran PT. Pertamina yang sebelumnya menguasai kegiatan usaha hulu sampai dengan hilir sektor migas. Dominasi asing terhadap sektor energi migas Indonesia akan semakin berkepanjangan apabila pemerintah tidak berupaya mendorong bangkitnya industri dalam negeri dan memberikan kesempatan yang lebih besar kepada industri lokal untuk ikut bermain di sektor ini sehingga beberapa tahun mendatang seluruh kegiatan usaha di sepanjang rantai nilai (value chain) pengelolaan migas, mulai dari industri hulu sampai hilir akan sepenuhnya dikuasai oleh industri dalam negeri, mulai dari industri besar, menengah, hingga industri berskala kecil. Hal ini sejalan dengan konsep klaster industri yang diperkenalkan oleh Porter (1998) dan kemudian diadopsi oleh pemerintah dengan mengeluarkan kebijakan pembangunan industri nasional dengan pendekatan klaster industri (Departemen Perindustrian, 2006).

Penelitian ini bertujuan untuk membuat sebuah model sistem dinamik klaster industri minyak bumi dan gas alam di Jawa Timur. Upaya peningkatan daya saing industri minyak bumi dan gas alam di Jawa Timur untuk mendukung peningkatan daya saing migas nasional di persaingan minyak bumi dan gas alam global dengan fokus pada salah satu sektor yang memiliki peran strategis dan potensial di Jawa Timur. Definisi dan identifikasi hubungan dari setiap komponen stakeholder dalam klaster sehingga dapat dibuat sebuah model sistem dinamik dari sistem migas Jatim tersebut sehingga dari model-model tersebut dapat diidentifikasi komponenkomponen (stakeholder) klaster, rantai nilai, model konseptual sistem industri minyak dan gas bumi di Jawa Timur, khususnya pada sektor pelumas sebagai embrio pengembangan klaster industri migas Jatim dan mampu menganalisis perilaku model klaster serta mengidentifikasi variabel-variabel yang mempengaruhi dan mendukung peningkatan daya saing klaster industri migas di Jawa Timur, khususnya pada industri pengolahan pelumas.

\section{METODE}

Secara metodologi penelitian ini menggunakan pendekatan mix method, yaitu gabungan antara metode kualitatif dan kuantitatif. Secara umum metode kualitatif dilakukan pada awal penelitian yang dilakukan dengan benchmarking kepada industri pelaku maupun asosiasi, in-depth interview dengan pakar, serta focus group discussion (FGD) dengan pelaku atau stakeholder. Di sisi lain, metode kuantitatif yang digunakan dalam penelitian ini adalah suatu alat pemodelan sistem yang disebut dengan sistem dinamis, di mana metode ini dimanfaatkan untuk mendapatkan gambar model dinamis klaster industri migas saat ini dan ke depannya seperti apa. Sistem dinamis juga digunakan untuk mensimulasikan beberapa model infrastruktur kebijakan pengembangan klaster industri minyak dan gas bumi di Jawa Timur untuk dapat ditentukan model terbaik.

Tahapan awal yang dilakukan dalam penelitian adalah mengidentifikasi sistem klaster industri minyak dan gas bumi di Jawa Timur, baik pelaku, hubungan antar pelaku dan kondisi sistem migas yang ada sehingga dapat didefinisikan rumusan 
masalah dan tujuan dari penelitian. Berlandaskan informasi kondisi sistem tersebut selanjutnya dilakukan diagnosis terhadap model stakeholder dan rantai nilai melalui penggalian data dengan penyebaran kusioner, Focus Group Discussion (FGD), brainstorming dan wawancara, serta in depth interview kepada para ekspert di sektor migas.

Tahapan selanjutnya adalah permodelan sistem daya saing industri migas Jatim, khususnya di industri pengolahan pelumas dengan menggunakan dinamika sistem. Beberapa tahapan yang dilakukan dalam permodelan ini adalah identifikasi variabel dalam sistem daya saing dan proses penggambaran sistem yang meliputi Model Boundary Diagram, Input Output Diagram, Cause Loop Diagram, dan Stock and Flow Diagram. Dengan menggunakan Vensim, model ini kemudian diformulasikan dan disimulasikan.

Tahapan terakhir dalam proses permodelan ini adalah dengan melakukan proses pengujian model yaitu pengujian verifikasi dan validasi model. Verifikasi model dilakukan dengan merunning model dan jika tidak terjadi "error" maka model dinyatakan telah terverifikasi. Sedangkan validasi dilakukan dengan menggunakan minitab, yaitu membandingkan nilai eksisting dan hasil simulasi dari sebuah parameter yang digunakan dalam model sistem, misalnya harga.

\section{Model Rantai Nilai dan Klaster Industri Migas}

Industri migas memiliki pohon industri yang cukup rumpun dari varietas produk yang bisa dihasilkan. Pada penelitian ini industri akan difokuskan pada industri petrochemical yang mengolah base oil menjadi lubricant (pelumas) karena di Jawa Timur pelaku pengolahan yang ada adalah industri pengolahan pelumas sebagaimana Gambar 1.

Tahapan diagnosis klaster industri dilakukan melalui studi literatur terhadap rantai produksi

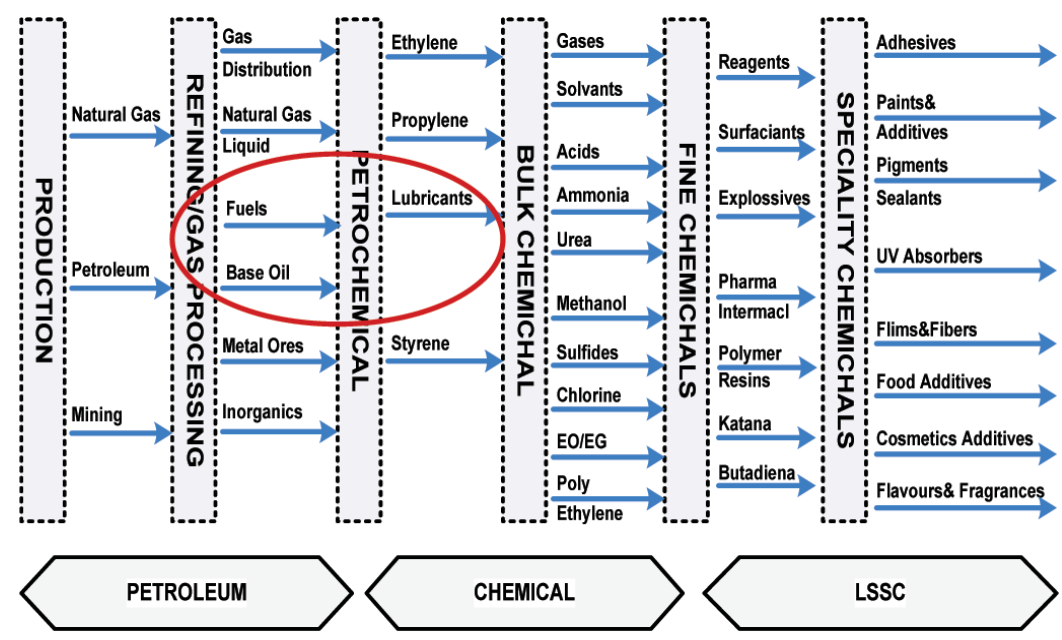

Gambar 1. Pohon Industri Minyak, Gas, dan Bahan Tambang

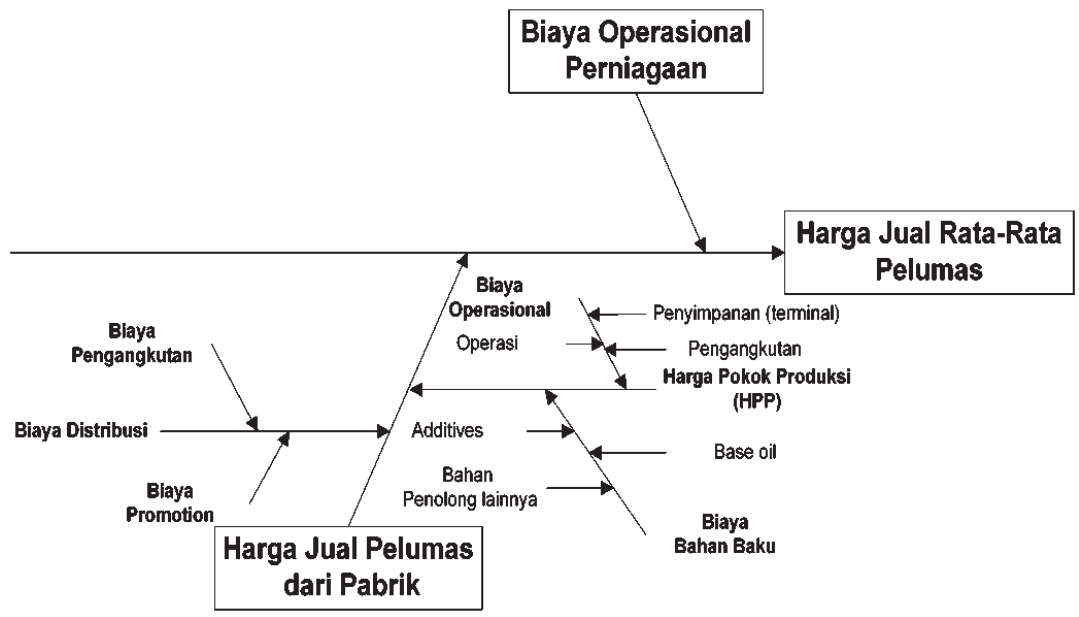

Gambar 2. Variabel-Variabel Pembentuk Nilai Tambah (Hasil FGD) 
berdasarkan data Dinas Energi dan Sumber Daya Mineral (ESDM) dan serta penggalian data primer melalui FGD serta in-depth interview ke beberapa pelaku, menghasilkan model rantai nilai klaster industri migas Jatim (Makky, 2006).

Dari rantai nilai klaster yang telah didiagnosis, selanjutnya diidentifikasi nilai tambah (add value) pada setiap rantai untuk didiagnosis profit margin yang dihasilkan dari rantai nilai secara keseluruhan.

Tabel 1. Variabel Daya Saing Industri Minyak dan Gas (Sumber: Competitiveness in The Brazilian Oil Industry- The Brazilian Oil diamond, 2000)

\begin{tabular}{lrl}
\hline \multicolumn{1}{c}{ Variabel Utama } & & \multicolumn{1}{c}{ Sub Variabel } \\
\hline Variabel Condition & $*$ & Potensi Kandungan Minyak Jatim \\
& $*$ Produksi base oil Jatim \\
& $*$ Minyak Tereksploitasi \\
& $*$ Infrastructure \\
& $*$ Ketersediaan Modal \\
& $*$ Kualitas base oil \\
& $*$ Harga base oil \\
& $*$ Human Capital Resources \\
& $*$ & Kondisi Social \\
\hline Demand Condition & $*$ & Konsumsi Product pelumas \\
& $*$ & Luas Cakupan Pasar pelumas \\
& $*$ & Jumlah import pelumas \\
& $*$ & Jumlah export pelumas \\
\hline Structure, strategy & $*$ & Produktivitas \\
and rivalry in & $*$ & Tingkat Kompetisi \\
companies & $*$ & Tingkat Science \\
& $*$ & Inovasi dan efisiensi \\
& $*$ & Cost \\
& $*$ & Variasi harga \\
& $*$ & Competitive firm \\
\hline Related \& & $*$ & Jumlah pelaku migas \\
Supporting Industry & $*$ & Hubungan pelaku migas \\
\hline Goverment & $*$ & Policy dan dukungan pemerintah \\
& $*$ & Pajak Migas \\
\hline & &
\end{tabular}

Variabel-variabel yang digunakan dalam menghitung nilai tambah setiap rantai nilai diberikan pada Gambar 2. Sedangkan hasil perhitungan nilai tambah dituangkan dalam diagram rantai nilai dan nilai tambah pada Gambar 3.

Berdasarkan diagnosis stakeholder dan rantai nilai ini maka diidentifikasi variabel daya saing dari industri migas di Jawa Timur berdasarkan Diamond Porter seperti pada Tabel 1.

\section{Pengembangan Model \\ Model Konseptual}

Tahap pengembangan model konseptual dilakukan mulai dari boundary system, inputoutput diagram, cause effect diagram, dan stock and flow diagram. Variabel yang digunakan dalam pengembangan model klaster daya saing adalah variabel yang telah discreening dengan pareto chart 80\%:20\% pada Tabel 1 berdasarkan tingkat kepentingan menurut pelaku migas Jatim sehingga representatif terhadap daya saing migas Jatim yang sebenarnya.

Tahap permodelan pertama adalah mendefinisikan boundary system agar model sistem lebih terfokus untuk kemudian dilanjutkan dengan mendefinisikan input-output diagram (Forester, 1968). Cause effect diagram daya saing klaster industri migas di Jawa Timur dengan variabel yang telah didefinisikan sebelumnya berdasarkan model Diamond Porter pada 4 faktor Diamond. Cause effect ini memberikan gambaran hubungan perilaku dari setiap variabel.

Gambar 3 merupakan beberapa contoh stock and flow diagram dari model daya saing klaster industri migas, khususnya pada industri pelumas. Setelah tahap permodelan tersebut, langkah selanjutnya adalah memformulasikan setiap variabel dalam

\begin{tabular}{|c|c|c|c|c|c|c|}
\hline \multicolumn{6}{|c|}{$\begin{array}{l}\text { Firm Infrastructure } \\
\text { si, Visi Misi Perusahaan, Strategy Objective }\end{array}$} & \multirow{9}{*}{$\begin{array}{l}\text { Profit margin = add value } \\
\text { (inbound logistic + operation + } \\
\text { outbound logistic + marketing \& } \\
\text { sales + services) } \\
\text { add value mineral = } \\
\text { supplier + operation + distributor } \\
=\text { Rp. } 3.201 .79 \\
\text { add value semi-syntheic = } \\
\text { supplier+operation + distributor } \\
=\text { Rp. } 5.872 .63 \\
\text { add value synthetic = } \\
\text { supplier+operation+distributor } \\
=\text { Rp. } 8.415 .49\end{array}$} \\
\hline \multicolumn{6}{|c|}{$\begin{array}{c}\text { Human Resources Development } \\
\text { Training Karyawan (Internal dan Eksternal) }\end{array}$} & \\
\hline \multicolumn{6}{|c|}{ Technology Development } & \\
\hline \multicolumn{6}{|c|}{ Otomation system controlling kilang by computerized optimation } & \\
\hline $\begin{array}{l}\text { Inbound } \\
\text { Logistic }\end{array}$ & Operation & Outb & id Logistic & $\begin{array}{l}\text { Marketing } \\
\text { and Sales }\end{array}$ & Service & \\
\hline $\begin{array}{c}\text { Add value } \\
\text { produk } \\
\text { supplier }\end{array}$ & $\begin{array}{c}\text { Add Value } \\
\text { Industri } \\
\text { Pengolahan }\end{array}$ & $\begin{array}{r}A d 0^{\prime} \\
p\end{array}$ & $\begin{array}{l}\text { ve Industri } \\
\text { impanan } \\
\text { umas }\end{array}$ & \multicolumn{2}{|c|}{$\begin{array}{c}\text { Add Value Niaga } \\
\text { (pengangkutan+niaga) }\end{array}$} & \\
\hline Rp2,428.11 & Mineral & $\mathrm{Rp}$ & 324.72 & Mineral & Rp 448.96 & \\
\hline $\mathrm{Rp} 2,868.97$ & semi-synth & Rp & $2,392.10$ & semi-synth & Rp 611.56 & \\
\hline $\mathrm{Rp} 3,860.90$ & synth & Rp & $3,237.81$ & synth & Rp $1,316.78$ & \\
\hline
\end{tabular}

Gambar 3. Rantai Nilai dan Nilai Tambah Klaster Industri Migas (Pengolahan Pelumas) 
sistem tersebut yang memberikan gambaran hubungan perilaku dalam sistem dan melakukan pengujian verifikasi dan validasi terhadap model.

\section{Pengujian Verifikasi dan Validasi}

Verifikasi dilakukan dengan merunning model dan melakukan check model dan check unit serta melihat cause tree diagram dari setiap sub model dan dilihat kelogisan sistem tersebut dalam model. Sedangkan validasi dilakukan dengan membandingkan output hasil simulasi dan data aktual (Forrester, 1968). Variabel yang menjadi parameter untuk divalidasi adalah harga pelumas per tipe.

\section{Uji Sensitifitas}

Setelah model dinyatakan terverifikasi dengan baik dan valid maka dilakukan uji sensitifitas dengan trial error dan membuat skenario kebijakan terkait dengan pengembangan klaster industri pelumas berdasarkan hasil analisa SWOT yang digali pada FGD. Dari hasil diskusi, skenario kebijakan yang akan disimulasikan adalah pada bea impor, iuran operasional, dan biaya sewa terminal.

\section{HASIL DAN PEMBAHASAN}

Rantai aktivitas migas terdiri atas aktivitas hulu-hilir di mana aktivitas hulu meliputi industri eksplorasi dan eksploitasi di mana terdapat 10 pelaku industri. Pelaku industri hulu yang tercatat ini mendapatkan ijin resmi dari ESDM dan BP Migas sebagai lembaga independen yang mengurusi ijin aktivitas hulu. Sedangkan pada area downstream industri hilir adalah industri pengolahan dan non pengolahan yang merupakan industri pendukung meliputi industri pengangkutan, penyimpanan dan perniagaan.

Pada industri pengangkutan, di Jawa Timur terdapat tiga kategori pengangkutan berdasarkan produk/bahan yang akan diangkut meliputi pengangkutan BBM, pengangkutan Gas, dan Pengangkutan LPG. Sedangkan berdasarkan wilayah dan cara pengangkutannya terdiri atas pengangkutan darat 14 perusahaan, laut (perairan Indonesia) 9 perusahaan, dan pipe line 4 perusahaan. Selain pengangkutan, industri hilir lainnya adalah penyimpanan yaitu penyimpanan LPG yang dipegang oleh Pertamina dan penyimpanan BBM yang dilakukan oleh tiga perusahaan penyimpanan BBM. Industri perniagaan juga dibedakan atas beberapa tipe perniagaan mulai dari perniagaan minyak, gas dengan fasilitas, gas dengan non fasilitas, niaga LPG, niaga BBM terbatas, niaga terbatas Olahan, niaga Recovered Oil, niaga CNG dan BBG, niaga umum hasil olahan, niaga BBM dan niaga BBM umum yang secara keseluruhan berjumlah 20 perusahaan perniagaan dengan ijin yang berbeda tergantung klasifikasi (Saiful, 2007).

Selain pelaku pendukung pada rantai migas tersebut, terdapat pula pelaku pendukung di luar rantai migas antara lain industri seismik, jasa konstruksi, industri peralatan dan industri jasa non produksi seperti industri jasa konsultan analisis. Di Jawa Timur ada sekitar 7 perusahaan konstruksi dan 5 perusahaan peralatan industri migas untuk industri pengolahan. Sedangkan untuk industri jasa non produksi meliputi jasa operasi sumur, pemboran, pekerjaan bawah tanah, inspeksi teknis dan sebagainya yang secara keseluruhan berjumlah sekitar 8 perusahaan jasa non produksi. Perusahaan jasa ini juga menjadi tim analisis terhadap kondisi tindakan migas yang akan dilakukan oleh perusahaan migas.

Selain hubungan antar pelaku industri inti dan pendukung, hubungan industri dengan pemerintah dan institusi penting lainnya juga harus dibangun secara kuat dan baik untuk mendukung pengembangan industri ini. Pemerintah daerah dan pemerintah pusat yang terdiri atas Departemen Energi dan Sumber Daya Mineral Pusat dan Propinsi Jawa Timur di bawah naungan Dirjen Minyak dan Gas Bumi dan Kementrian ESDM, BUMD, dan BKPM merupakan instansi pemerintah yang memiliki peran penting dalam kaitannya dengan penetapan kebijakan terkait dengan aktivitas migas. Dirjen Pajak dan Bea Cukai, Perbankan Nasional dan BUMN terkait seperti TELKOM, PLN merupakan institusi pemerintah yang secara langsung maupun tidak langsung mendukung akivitas migas dalam hal kebijakan pajak, financial, dan infrastruktur.

Selain pemerintah, stakeholder lain yang mendukung keberlangsungan klaster migas adalah asosiasi, lembaga penelitian, dan masyarakat. Beberapa asosiasi migas antara lain Aspelindo, Aspermigas, Apitindo, Inpemigas, Hiswana Migas dan Komunitas Migas Indonesia. Lembaga lainnya adalah Lembaga penelitian dalam kaitannya dengan pengembangan industri migas dan perguruan tinggi sebagai pencetak kader dan menghasilkan sumber daya manusia yang memiliki kompeten. Sedangkan masyarakat, Lembaga Swadaya masyarakat, tokoh masyarakat dan penduduk setempat merupakan sasaran sosial perusahaan dalam mengimplementasikan Corporate Social Responsibility kepada lingkungan sekitar industri.

Base oil merupakan bahan baku utama dalam pembuatan pelumas. Ketidaktersediaan base oil secara mandiri sebagai bahan baku pelumas dalam memenuhi kebutuhan produksi pelumas di Jawa Timur merupakan aspek yang perlu 
dipertimbangkan dalam pengembangan klaster industri migas ke depannya. Dukungan pemerintah baik secara financial maupun infrastruktur dalam pembangunan dan pengadaan industri pengolahan refinery yang mampu menghasilkan base oil akan membantu meningkatkan efisiensi industri ini karena saving cost dari transportasi dan terminal pengangkutan bisa dioptimalkan di sini.

Melihat rantai nilai dari industri pelumas dan berdasarkan hasil pengolahan data diketahui bahwa nilai tambah di aktivitas primer mulai inbound logistic, operation, outbound logistic, marketing, sales dan service berturut-turut adalah Rp. 2.428 per liter untuk inbound logistic base oil untuk pelumas mineral, semi synthetic dan synthetic, serta inbound logistic Rp. 440,86 per liter dan Rp. 991,93 per liter additives untuk semi synthetic dan synthetic berturutturut; pada operation dan outbound logistic Rp. 324,72 per liter untuk pelumas mineral, Rp. 2.392,10 per liter untuk pelumas semi-synthetic dan Rp. 3.237,81 per liter untuk pelumas synthetic; pada marketing, sales dan services $\mathrm{Rp}$. 448.96 per liter untuk pelumas mineral, Rp. 611.56 untuk pelumas semi-synthetic dan Rp. 1.316,78 per liter untuk pelumas synthetic; sehingga nilai tambah rata-rata yang diberikan pada pelumas untuk setiap tipenya secara indikatif adalah Rp. 3.201 per liter untuk pelumas mineral, Rp. 5.872,63 per liter untuk pelumas semi-synthetic, dan Rp 8.415,49 per liter untuk pelumas synthetic.

Berdasarkan informasi tersebut diketahui bahwa nilai tambah terbesar sebenarnya terdapat pada pada inbound karena harga bahan baku base oil yang cukup tinggi apalagi base oil tersebut merupakan base oil impor sebagai akibat dari ketidaktersediaan base oil lokal. Selain harga base oil, harga bahan additive untuk pelumas tipe synthetic yang cukup tinggi dan biasasnya diimpor merupakan alasan yang juga mempengaruhi add value di rantai ini cukup tinggi jika dibandingkan dengan rantai yang lain. Jika dilihat dari harga komoditas pelumas rata-rata add value yang diberikan kepada produk rata-rata hanya $14 \%$, di mana inbound logistic dan operation ini menyumbang $7 \%$ dan 5\% dari rata-rata harga jual pelumas di pasar sedangkan aktivitas setelah itu hanya menyumbang sekitar $2 \%$ untuk produk pelumas yang ada di pasar. Proporsi $12 \%$ nilai nominal ekonomis terhadap harga jual tersebut pada rantai inbound dan operation selain disebabkan oleh harga base oil yang cukup mahal juga disebabkan oleh biaya operasional yang cukup tinggi karena teknologi untuk proses produksi khususnya pada produk semisynthetic dan synthetic yang cukup tinggi. Tingginya nilai investasi dan resiko yang akan ditanggung oleh industri ini sejalan dengan konsep high risk, high return
Biaya produksi dinyatakan sebagai kumpulan biaya langsung yang meliputi biaya bahan baku, tenaga kerja langsung, overhead pabrik, dan beberapa biaya operasional lainnya sehingga diketahui biaya pokok produksinya (Widianto, 2007). Variabel tenaga kerja dengan keahlian yang baik, investasi, depresiasi peralatan dan konstruksi kilang serta biaya overhead lainnya merupakan beberapa variabel pemicu rantai yang memberikan konstribusi besar dalam nilai pelumas pada sektor migas. Nilai tambah dari rantai ini merupakan nilai tambah tertinggi pada rantai pengolahan pelumas.

Selain pada aktivitas pengolahan dan inbound logistic, nilai tambah aktivitas outbound logistic, marketing and sales, dan service juga mampu memberikan konstribusi dalam menentukan profit margin dalam produk pengolahan pelumas. Nilai tambah pada aktivitas ini tidak lebih besar dari aktivitas operation dan outbound karena memang aktivitas ini tidak memberikan nilai tambah secara fungsional pada produk pelumas. Aktivitas tersebut merupakan aktivitas penyimpanan, pengangkutan dan perniagaan produk pelumas. Peningkatan strategi marketing and sales serta service untuk pelanggan produk pelumas mampu menaikkan kepuasan customer sehingga mampu meningkatkan loyalitas dari customer untuk menggunakan produk pelumas yang dihasilkan perusahaan ataupun klaster.

Dari hasil diagnosis rantai nilai juga diketahui bahwa profit margin dari produk olahan minyak pelumas sebesar Rp 3.201,79 per liter untuk pelumas mineral, Rp. 5.872,63 per liter untuk pelumas semisynthetic, dan Rp. 8.415,49 per liter untuk pelumas synthetic. Profit margin ini bisa ditingkatkan dengan meningkatkan kinerja klaster industri di sektor ini secara maksimal. Oleh karena itu dalam pengembangan klaster ke depannya pemerintah bisa mempertimbangkan peran strategis industri pengolahan refinery ini ada dan beroperasi secara optimal di Jawa Timur sehingga dapat meningkatkan efisiensi cost dan meningkatkan daya saing industri. Konsep outsourcing produk ke industri lain dan fokus pada salah satu produk olahan unggulan perusahaan saja merupakan salah satu strategi yang cukup efektif untuk meningkatkan daya saing industri. Strategi ini dapat meningkatkan efektifitas dan keuntungan perusahaan. Selain kerjasama antar pelaku, identifikasi nilai tambah dari setiap chain dalam perusahaan yang kurang mampu memberikan nilai tambah yang besar dapat diminimalisasi dengan melakukan pemutusan rantai dan menyatukannya dalam sebuah rantai lain sehingga lebih efektif. 
Pada value chain Porter juga terdapat aktivitas sekunder yang dilakukan dalam sebuah industri ataupun perusahaan (Porter, 1998). Aktivitas tersebut meliputi aktivitas strategis yaitu firm infrastructure yang merupakan gambaran dari struktur organisasi yang digunakan, visi dan misi perusahaan, strategi objective, sistem pengendalian dan pembentukan budaya perusahaan, Human Resource Management, Technology Development, dan Procurement. Aktivitas firm infrastructure merupakan bagian top management yang memiliki peran strategis dalam pengembangan perusahaan. Adanya pendefinisian visi misi perusahaan, langkah strategis perusahaan, serta sistem management yang baik akan mendorong peningkatan kinerja perusahaan karena hal ini berkaitan dengan kelegalan dan prospek profitability perusahaan ke depannya dalam memandang secara visioner terhadap persaingan yang ada sehingga dapat menentukan langkah-langkah strategis management dalam menghadapi tantangan ke depan.

Sistem pengendalian dalam setiap business process yang dituangkan dalam design pengendalian secara teknis, human resource maupun sumber daya yang lain merupakan langkah taktis management dalam penentuan strategi pencapaian visi misi perusahaan dengan menciptakan budaya kerja yang kondusif dan kompetisi yang sehat di dalam perusahaan. Aktivitas sekunder lainnya adalah terkait dengan human resource management yang merupakan aspek sangat penting karena sumber daya yang diatur disini adalah sumber daya manusia. Kinerja manusia tidak bisa disamakan dengan mesin dan modal kapital yang sifatnya statis dan bisa diatur. Oleh karena itu management terhadap sumber daya manusia perlu diatur secara baik dan maksimal. Dalam perkembangan manajemen sumber daya manusia, aktivitas MSDM meliputi aktivitas recruitment, training, pengembangan karyawan, kompensasi, penilaian kinerja (evaluasi) dan aktivitas penting lainnya yang terkait. Training karyawan merupakan aktivitas peningkatan skill karyawan agar dapat meningkatkan kompetensi perusahaan

Aktivitas sekunder yang lain adalah procurement. Penyediaan bahan baku adalah aspek penting yang mendukung kelancaran aktivitas produksi perusahaan. Kerugiaan akibat keterlambatan kedatangan bahan baku sehingga produksi tidak bisa dilakukan merupakan resiko besar yang dihadapi perusahaan ketika management procurement tidak menjalankan fungsinya secara lancar. Konsep klaster industri merupakan solusi konsep yang patut dipertimbangkan untuk masalah ini. Karena dalam konsep klaster keterkaitan dan kerjasama dari setiap pelaku industri di klaster tersebut dinyatakan dalam sebuah komitmen bersama dalam mendukung keberlangsungan dan berkembangnya sektor ini.

Peningkatan peran oleh setiap pelaku dalam klaster dapat meningkatkan efektifitas dari masing-masing pelaku dalam klaster industri itu sendiri sehingga dapat meningkatkan daya saing industri. Penggambaran model daya saing industri pelumas di Jawa Timur dengan menggunakan Model Diamond Porter merupakan metode untuk melihat gambaran perilaku dalam sistem migas saat ini. Berdasarkan hasil simulasi untuk model daya saing secara keseluruhan diketahui bahwa daya saing industri pelumas di Jawa Timur tahun 2009 adalah 2,23 . Artinya daya saing industri pelumas di Jawa Timur ini masih rendah. Hal ini disebabkan karena masih minimnya dukungan dari berbagai pihak, baik industri pendukung maupun industri terkait, pemerintah dan lembaga pendukung lainnya dalam mendukung pengembangan industri ini sebagai upaya peningkatan daya saing.

Berdasarkan hasil simulasi tersebut diketahui bahwa variabel yang memberikan konstribusi rendah dalam daya saing industri pelumas adalah factor condition, demand condition, dan related supporting industry. Factor condition memberikan konstribusi indeks daya saing hanya 2.18 , artinya konstribusi variabel ini masih sangat rendah. Hal ini disebabkan karena ketersediaan base oil di Jawa Timur masih belum cukup memenuhi kebutuhan lokal bahkan tidak ada. Hal ini menimbulkan biaya tambahan karena pelaku harus mengalokasikan dana penyediaan bahan tambahan untuk transportasi dan terminal penyimpanan maupun bongkar muat bahan baku base oil tersebut. Selain itu kurangnya daya dukung infrastruktur dan kebijakan pemerintah terkait infrastruktur tersebut dilihat dari indeks konstribusi infrastruktur di Jawa Timur yang masih rendah menimbulkan indeks konstribusi infrastruktur terhadap factor condition kecil. Begitu juga demand factor, variabel ini memiliki indeks kecil dalam mendukung indeks daya saing hal ini dikarenakan luas cakupan pasar di Jawa Timur untuk masing-masing pelaku sangat berbeda jauh sehingga kondisi daya saing pelumas oleh pelaku ini masih didominasi oleh pelaku tertentu saja sehingga daya saing antar pelaku di dalam klaster tersebut untuk memenuhi permintaan pelumas yang semakin meningkat rendah. Sedangkan related supporting industry memberikan konstribusi yang paling rendah pada tahun 2009 karena tidak adanya supplier bahan baku base oil di Jatim dan pelaku pendukung lainnya yang kurang mampu mendukung aktivitas migas seperti pengangkutan, penyimpanan dan sebagainya. 
Melihat output simulasi dari daya saing klaster industri pelumas di Jawa Timur yang masih rendah tersebut maka perlu dibuat sebuah rekomendasi terkait dengan kebijakan migas menanggapi fenomena tersebut. Berdasarkan hasil simulasi skenario model akan dilakukan terhadap kebijakan bea, iuran operasional, dan sewa terminal yang diidentifikasi dari analisa SWOT pada FGD ternyata tidak mampu memberikan pengaruh yang cukup signifikan terhadap daya saing klaster industri pelumas dalam mendukung daya saing industri migas di Jatim. Namun jika diuji sensitivitas pada beberapa parameter variabel secara trial error dalam model tersebut diketahui bahwa variabel yang mampu memberikan pengaruh signifikan terhadap daya saing industri pelumas adalah keberadaan jumlah sektor pengangkutan. Hal ini mengindikasikan bahwa keberadaan sektor pengangkutan di Jawa Timur masih belum memberikan konstribusi yang besar dalam mendukung keberlangsungan dan daya saing industri pelumas khususnya dan migas secara umum. Kondisi infrastruktur yang kurang mendapat dukungan dari pemerintah dan keterbatasan armada adalah beberapa alasan yang parameter berpengaruh terhadap peningkatan daya saing klaster industri pelumas.

\section{SIMPULAN}

Stakeholder klaster industri migas terdiri atas pelaku inti yaitu industri pengolahan dan industri terkait yang meliputi eksplorasi-ekploitasi, pengangkutan, penyimpanan, dan perniagaan. Sedangkan pelaku pendukungnya terdiri atas industri peralatan, jasa konstruksi, jasa non produksi, seismic, jasa analis dan sebagainya. Selain itu lembaga atau institusi yang juga mendukung meliputi BP Migas, BPH Migas, Lembaga Penelitian seperti LPPM ITS, LAPI ITB, dan perguruan tinggi lainnya, pemerintah pusat dan daerah, asosiasi, masyarakat dan perguruan tinggi. Ada beberapa variabel daya saing yang berpengaruh dalam peningkatan daya saing klaster industri pelumas yaitu factor condition yang dipengaruhi oleh variabel ketersediaan SDM, SDA, modal, infrastruktur yang baik serta harga base oil, dan kondisi sosial masyarakat sekitar industri; demand condition meliputi variabel tingkat konsumsi permintaan pelumas dan luas cakupan pasar pelumas yang mampu dipenuhi oleh industri pengolahan pelumas di Jawa Timur. Dari hasil simulasi diketahui daya saing industri pelumas dalam mendukung daya saing industri migas secara umum masih rendah. Hal ini karena dukungan dari pelaku pendukung dan pemerintah masih belum mampu memenuhi kebutuhan industri baik secara teknis maupun operasional.

\section{DAFTAR PUSTAKA}

Badan Pusat Statistik. 2009. Pertumbuhan Ekonomi Indonesia Tahun 2008. Berita Resmi Statistik. Badan Pusat Statistik. <URL: http://www.bps.go.id>. Diakses 25 Agustus 2009.

Badan Pengelola Usaha Hilir Minyak dan Gas Bumi. 2009. Blueprint BPH Migas. <URL: http://www.bphmigas. go.id.html>. Diakses 1 Juni 2009.

Bank Indonesia, 2009. Inflasi <URL; http://www.bi.go. $i d>$.

Departemen Energi dan Sumber Daya Mineral. 2004. Pedoman dan Pola Tetap kebijakan Pemanfaatan Gas Bumi Nasional 2004/2005; Blueprint Implementasi Undang-Undang No. 22 tahun 2001 tentang Minyak dan Gas Bumi. <URL: http://www.bphmigas.go.id>. Diakses 1 Juni 2009.

Departemen Energi dan Sumber Daya Mineral. 2005. KPS, Blok, Cadangan Minyak dan Gas Bumi di Jawa Timur. <URL: http://www.jatimprov.go.id.html>. Diakses 27 Agustus 2009.

Departemen Energi dan Sumber Daya Mineral. 2009. Industri Migas Aman Bagi Perbankan Nasional. $<U R L$ : http://www.esdm.go.id>. Diakses 27 Juli 2009.

Departemen Perindustrian. 2006. Bangun Sektor Industri Tahun 2025 Bab V. PT. Sucofindo. Jakarta.

Direktorat Jendral Minyak dan gas Bumi. 2008. Datawarehouse. Departemen Energi dan Sumber Daya Mineral. <URL: http://www.migas.esdm.go.id>.

Forrester, J.W. 1968. Principle of System. Wright-Allen Press, Inc. Massachusetts.

Gutomo, Prayudo. 2008. Potensi Migas dan Pengembangan SDM Daerah. <URL: http://www.pks-jatim.org>. Diakses 1 Juni 2009.

Kadin Indonesia. 2007. Visi 2030 dan Road Map 2010 Industri Nasional. Ringkasan Eksekutif Rekomendasi Kadin Indonesia.

Makky, S.J. 2006. Pengelolaan Sumber Daya Energi dan mineral di Jawa Timur. Pusat Penelitian Kebumian dan Eksplorasi Sumber Daya Alam. Ketua Kelompok Riset Teknologi Pencitraan Geofisika dan Dinamika Fluida. Laboratorium Geofisika, Fisika FMIPA, ITS Surabaya.

Partiwi, S.G. 2007. Perancangan Model Pengukuran Kinerja Komprehensif pada Sistem Klaster Agroindustri. Disertasi Institut Pertanian Bogor.

Pertamina, 2009. Daftar Produk-Unit Bisnis Pelumas. PT.Pertamina. <URL: http://pelumas.pertamina. com>.

Porter, M.E. 1998. Cluster and The New Economic of Competition. Harvards Business Review.

Saiful, R.A . 2007. Migas jatim Dikuasai dan Siap Dieksploitasi "Dajjal Kapitalisme" <URL: http://www.ipoel.wordpress.com.html>. Diakses 9 September 2009.

Sasli, Rais dan Dance, Y.F. 2009. Penguatan Daya Saing Daerah untuk Mendukung Industri Kluster. Project Management Unit (PMU) Badan Perencanaan 
Pembangunan Nasional, PNPM Mandiri Daerah Tertinggal dan Khusus. Nangroe Aceh DarussalamNias.

Tempo Interaktif. 2004. UU No. 22 Tahun 2001 tentang minyak dan gas bumi. <URL: http://www. tempointeraktif.com $>$. Diakses 30 Agustus 2009.

Widianto, Eko. 2007. Kondisi Energi Primer (Minyak dan Gas) Indonesia. Pertemuan Nasional Forum Komunikasi Pendidikan Tinggi Elektro Indonesia 2007. Yogyakarta.

Zamith, Regina. 2000. Competitiveness in The Brazillian Oil Industry-The Brazilian (Oil Diamond). Energy Program. University of Sao Paulo, Brazil. Revue de l'Energie, No. 516. 